\title{
Cephalometric Comparison of Wits Appraisal and APP-BPP to the ANB Angle
}

\author{
Dr Sanzee Silwal,' Dr Rabindra Man Shrestha,2 Dr Ujjwal Pyakurel,3 Sanjeev Bhandari \\ 'PG Resident, ${ }^{2}$ Prof \& HOD, ${ }^{3}$ Asst Prof, 4 Intern \\ Department of Orthodontics, Kantipur Dental College, Kathmandu, Nepal
}

\section{ABSTRACT}

Introduction: Great emphasis has been given to the evaluation of sagittal apical base relationship in orthodontic diagnosis and treatment planning. Supposedly, the most commonly used parameter is "ANB angle"; however its accuracy and reliability have been questioned. Many authors have alternatively introduced linear parameters like Wits appraisal and APP-BPP. The objective of the study was to compare Wits appraisal and APP-BPP with the ANB angle.

Materials \& Method: This study was conducted on patients visiting the Department of Orthodontics, Kantipur Dental College, Kathmandu. The sample included 100 lateral cephalograms of subjects of the age group 18-30 years with skeletal Class I relation. Parameters like ANB angle, Wits appraisal and APP-BPP were measured to assess the sagittal jaw relationship. Descriptive statistics were calculated for each parameter. Spearman's test was done to evaluate the correlation between the parameters. Mann-Whitney $U$ test was done to compare the parameters between male and female subjects.

Result: Descriptive statistics showed that the mean values of ANB, Wits appraisal and APP-BPP were $2.26 \pm 1.19^{\circ}, 0.38 \pm 0.87 \mathrm{~mm}$ and $3.25 \pm 1.20 \mathrm{~mm}$ respectively. Mann-Whitney $U$ test showed no significant difference among the parameters between the gender groups ( $p>0.05$ ). Spearman's test showed significant correlation among the parameters ANB angle, Wits appraisal and APP-BPP. The parameters had strong positive correlation as $r$ value was greater than 0.7 .

Conclusion: The strong positive correlation between ANB angle, Wits appraisal and APP-BPP indicates that these parameters can be used as better adjunct to ANB angle in orthodontic diagnosis and treatment planning.

Keywords: ANB angle, APP-BPP parameter, Sagittal apical base relationship, Wits appraisal.

\section{INTRODUCTION}

Assessment of sagittal jaw relationship is crucial in orthodontic diagnosis and treatment planning. Various linear and angular parameters have been proposed to detect sagittal jaw disharmonies. The most commonly used parameter, the "ANB angle" introduced by Riedel relates jaws to anterior cranial base (SN) plane..$^{1-4}$

Evaluating the jaws to cranial reference planes produces inconsistencies due to variations in craniofacial structures. It is well acknowledged that the change in position of nasion and rotation of the jaws during growth affect the ANB value. ${ }^{5}$ Thus, various authors have developed other analyses to eliminate the use of cranial reference planes.

Jacobson developed "Wits" appraisal of jaw disharmony relating the jaw bases to the occlusal plane. ${ }^{6}$ It eliminates the use of cranial landmarks and prevents geometric inconsistencies. Nanda and Merrill introduced APP-BPP measurement based on the palatal plane. According to them, the palatal plane has minimal changes in inclination from age 6 years to adulthood and can be used as a stable plane of reference for assessing sagittal jaw relationships. ${ }^{7}$ Assessment by linear measurements has advantages over angular measurements because there are fewer variables to affect their accuracy and there is less error of measurement.

The objectives of this study were to compare and correlate Wits appraisal and APP-BPP with the "ANB angle." In literature, there are limited researches done in Nepali subjects giving insight about sagittal jaw relationship. . $^{-11}$ The information obtained from this study will help clinicians comprehend the linear parameters in assessing the sagittal jaw relationship and utilize them as an adjunct to ANB angle.

\section{MATERIALS AND METHOD}

The present study is a non-interventional observational descriptive study using secondary data. It was conducted 
at the Department of Orthodontics, Kantipur Dental College Teaching Hospital and Research Center, Kathmandu during January to February 2020 after obtaining the ethical clearance from the Institutional Review Committee.

The sampling technique used was non-probability convenient technique. The sample size was determined based on the number of patients who sought orthodontic treatment at the Department of Orthodontics, Kantipur Dental College in reference to study done by Acharya et al ${ }^{12}$ using the following formula:

$$
\text { Sample size }(n)=\frac{\frac{z^{2} p q}{e^{2}}}{\left[1+\frac{z^{2} p q}{e^{2} \cdot N}\right]}
$$

Where, $z=1.96, p=79.33 \%, q=20.67 \%$, $e=0.05$, and $\mathrm{N}=$ number of patients visiting the department with Skeletal Class I relation in a period of 6 months $=100$.

Lateral cephalograms were visually inspected from the records of the patients seeking orthodontic treatment. A total of 150 lateral cephalograms were traced and 100 superior samples were selected for the study. Independent variables were age and gender groups while dependent variables were cephalometric parameters. The linear parameters were Wits appraisal (AO-BO) and APP-BPP and the angular parameter was ANB angle.

Samples were selected on the basis of the selection criteria. Nepali subjects aged 18-30 years with skeletal Class I relation (ANB: $2 \pm 2^{\circ}$ ) having full complement of teeth (excluding third molars) were included in the study. Only high quality pretreatment lateral cephalograms and panoramic radiographs were evaluated. Subjects who had previously undergone orthodontic or dentofacial orthopedic treatment, history of trauma to craniofacial region, gross craniofacial asymmetry, deformities were excluded from the study.

Lateral cephalograms were previously taken following the standard radiographic protocol. The radiographs were traced on matte acetate tracing paper with $2 \mathrm{~B}$ sharp pencil on a view box using trans-illuminated light. The landmarks and measurements were marked manually by a single examiner. Cephalometric landmarks used in the study were Point A, Point B, Sella (S), Nasion (N), Anterior Nasal Spine (ANS) and Posterior

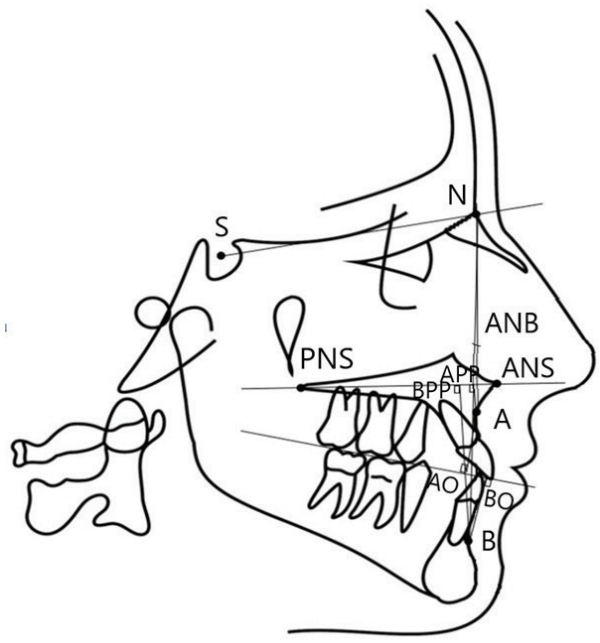

Figure 1. Cephalometric landmarks and parameters

Nasal Spine (PNS). Cephalometric planes used in the study were functional occlusal plane and palatal plane. The functional occlusal plane was drawn by bisecting the molars and premolars and the palatal plane was drawn by joining ANS and PNS.

Cephalometric angular parameters used in the study were SNA, SNB and ANB. Cephalometric linear parameters were Wits appraisal (AO-BO) and APP-BPP. To measure $\mathrm{AO}-\mathrm{BO}$ and APP-BPP, perpendicular lines were drawn from point $A$ and point $B$ to the occlusal (AO and $\mathrm{BO}$ ) and palatal planes (APP and BPP) (Figure $1)$.

$\mathrm{AO}$ and $\mathrm{BO}$ are the points of contact in the occlusal plane, whereas APP and BPP are the points of contact on the palatal plane. The distances between the intersected points were measured. The distance between points $A O$ and $B O$ is known as the Wits appraisal. The linear distance between APP and BPP is given by APP-BPP.

Data was collected, compiled and analyzed by using SPSS V. 21. To check the normality of distribution of the data, Kolmogorov Smirnov test was done. The data was not normally distributed. The descriptive statistics of linear and angular parameters were evaluated. Descriptive statistics like mean, standard deviation and range was calculated for each parameter. Spearman's test was done to evaluate the correlation among the parameters. Mann-Whitney $U$ test was done to compare the parameters between male and female subjects. $\mathrm{p}$-Value $<0.05$ were considered significant. 
Table 1. Descriptive statistics of linear and angular parameters

\begin{tabular}{|c|c|c|c|c|}
\hline Parameter & Mean \pm SD & Maximum & Minimum & Range \\
\hline SNA $\left(^{\circ}\right)$ & $80.75 \pm 3.34$ & 88.00 & 73.00 & 15.00 \\
\hline SNB $\left(^{\circ}\right)$ & $78.48 \pm 2.96$ & 85.00 & 71.00 & 14.00 \\
\hline ANB $\left(^{\circ}\right)$ & $2.26 \pm 1.19$ & 4.00 & 0.00 & 4.00 \\
\hline Wits $(\mathrm{mm})$ & $0.38 \pm 0.87$ & 2.50 & -1.50 & 4.00 \\
\hline APP-BPP $(\mathrm{mm})$ & $3.25 \pm 1.20$ & 5.50 & 1.00 & 4.50 \\
\hline
\end{tabular}

Table 2. Spearman correlation test to determine relation between parameters

\begin{tabular}{|c|c|c|c|}
\hline \multicolumn{2}{|c|}{ Parameters } & "r" value & $p$ Value \\
\hline ANB & Wits & $0.746 \wedge$ & $0.00^{*}$ \\
\hline Wits & APP-BPP & $0.762 \wedge$ & $0.00^{*}$ \\
\hline APP-BPP & ANB & $0.868 \wedge$ & $0.00^{*}$ \\
\hline
\end{tabular}

*Statistical significance at $p$ value $<0.05, \wedge$ Strong positive correlation at $r$ value $>0.7$

Table 3. Comparison of parameters between male and female subjects

\begin{tabular}{|c|c|c|c|}
\hline Parameter & Gender & Mean $\pm S D$ & $p$ Value \\
\hline \multirow{2}{*}{ SNA $\left({ }^{\circ}\right)$} & Male & $80.77 \pm 3.08$ & \multirow{2}{*}{0.917 (NS) } \\
\hline & Female & $80.73 \pm 3.62$ & \\
\hline \multirow{2}{*}{ SNB $\left({ }^{\circ}\right)$} & Male & $78.56 \pm 2.76$ & \multirow{2}{*}{0.774 (NS) } \\
\hline & Female & $78.41 \pm 3.11$ & \\
\hline \multirow{2}{*}{ ANB $\left({ }^{\circ}\right)$} & Male & $2.27 \pm 1.10$ & \multirow{2}{*}{0.944 (NS) } \\
\hline & Female & $2.26 \pm 1.28$ & \\
\hline \multirow{2}{*}{ Wits (mm) } & Male & $0.33 \pm 0.84$ & \multirow{2}{*}{0.607 (NS) } \\
\hline & Female & $0.43 \pm 0.909$ & \\
\hline \multirow{2}{*}{ APP-BPP (mm) } & Male & $3.26 \pm 1.30$ & \multirow{2}{*}{0.880 (NS) } \\
\hline & Female & $3.24 \pm 1.20$ & \\
\hline
\end{tabular}

NS: Not significant

\section{RESULT}

The sample consisted of one hundred lateral cephalograms of the subjects aged between 18 and 30 years. The mean age of the total sample was 20.80 \pm 2.91 years. There were equal proportion of male and female samples in each group.

Descriptive statistics of linear and angular parameters are given in Table 1. The results from Spearman correlation test and Mann-Whitney $U$ test are given in Table 2 and Table 3 respectively.

The mean values of ANB, Wits appraisal and APPBPP were $2.26 \pm 1.19^{\circ}, 0.38 \pm 0.87 \mathrm{~mm}$ and $3.25 \pm 1.20 \mathrm{~mm}$ respectively (Table 1). There was a positive correlation among the parameters ANB angle, Wits appraisal and APP-BPP. The parameters had strong positive correlation as $r$ value was greater than 0.7 (Table 2).

The mean values of ANB and APP-BPP were higher in male than female. In contrast, the mean values of
Wits appraisal were higher in female. However, the differences were not significant (Table 3).

\section{DISCUSSION}

The Wits appraisal and APP-BPP are linearmeasurements of sagittal disharmonies based on functional occlusal plane and palatal plane respectively. The mean values for Wits appraisal and APP-BPP in the present study were $0.38 \pm 0.87 \mathrm{~mm}$ and $3.25 \pm 1.20 \mathrm{~mm}$ respectively which is in accordance with the study done by Pyakurel et al $^{11}$ in Nepali subjects where Wits appraisal was $0.38 \pm 3.331 \mathrm{~mm}$ and APP-BPP was $3.291 \pm 4.285 \mathrm{~mm}$ for the age group 15-25 years. However, the values are inconsistent with respect to age group 26-34 years where the values for Wits appraisal and APP-BPP were $0.05 \pm 3.796 \mathrm{~mm}$ and $4.20 \pm 3.075$ respectively. These differences could be due to variation in the age group selected for the study.

The mean Wits values among male and female in this study were $0.33 \pm 0.84 \mathrm{~mm}$ and $0.43 \pm 0.909 \mathrm{~mm}$ 
respectively, which are incomparable with the study done by Jacobson' ${ }^{6}$ on Caucasians where the values were $1.17 \pm 1.9 \mathrm{~mm}$ and $-0.10 \pm 1.77 \mathrm{~mm}$ respectively. Similarly, the mean value of APP-BPP among male and female in this study were $3.26 \pm 1.30 \mathrm{~mm}$ and $3.24 \pm 1.20 \mathrm{~mm}$ respectively. However, the mean values for White male and female were $5.2 \pm 2.9 \mathrm{~mm}$ and $4.8 \pm 3.6 \mathrm{~mm}$ respectively. ${ }^{7}$ These discrepancies could be due to the racial variation.

The present study showed strong positive correlation ( $r$ value $>0.7$ ) between the parameters studied. These findings are in accordance with the study done by Italia and Bhatia. ${ }^{13}$ Likewise, Rotberg et al also found statistically significant positive correlation between ANB values and Wits values. ${ }^{14}$

Soliman et al concluded that the Wits appraisal and APP-BPP could be used alternatively with ANB angle particularly when identification of Nasion point is difficult. ${ }^{15}$ Thus, the Wits appraisal and APP-BPP parameters can be used for determining the sagittal jaw relationship more reliably.
The study was conducted among the patients visiting Kantipur Dental College and Hospital. So the data does not represent the wider population. The study was based on lateral cephalogram which is a two dimensional representation of three dimensional structure.

\section{CONCLUSION}

When the reliability of ANB angle is questionable, the underlying sagittal skeletal dysplasia can be assessed by the parameters Wits appraisal and APP-BPP. The strong positive correlation between ANB angle, Wits appraisal and APP-BPP indicates that these parameters can be used as an adjunct to ANB angle in orthodontic diagnosis and treatment planning.

\section{ACKNOWLEDGEMENT}

We would like to thank Dr Sujita Shrestha, Lecturer, Department of Community \& Public Health Dentistry for her kind cooperation in the statistical analysis of the data.

\section{OJN}

\section{REFERENCES}

1. Riedel RA. The relation of maxillary structures to cranium in malocclusions and normal occlusion. Angle Orthod. 1952 Jul;22(3):142-5.

2. Jacobson A, Jacobson RL. Radiographic cephalometry from basics to 3-D imaging. 2nd ed. Chicago: Quintessence Pub; 2006. $99-111$ P

3. Taylor CM. Changes in relationship of nasion, point A and point B effect on ANB. Am J Orthod. 1969 Aug;56(2):143-63.

4. Beatty EJ. A modified technique for evaluating apical base relationships. Am J Orthod. 1975 Sep;68(3):303-15.

5. Hussels W, Nanda RS. Analysis of factors affecting angleANB. Am J Orthod. 1984 May;85(5):41 1-23.

6. Jacobson A. The "Wits" appraisal of jaw disharmony. Am J Orthod. 1975;67(2):125-38.

7. Nanda RS, Merrill RM. Cephalometric assessment of sagittal relationship between maxilla and mandible. Am J OrthodDentofacialOrthop 1994:105:328-44.

8. Parajuli U, Mishra P, Bhattarai P, Bajracharya M, Tuladhar SL. Comparison of Downs analysis amongst Nepalese ethnic groups - Brahmins, Hindu Newars and Buddhist Newars. J Nepal Dent Assoc. 2013;13(1):10-4.

9. Sharma JN. Steiner's cephalometric norms for the Nepalese population. J Orthodont. 2011;38:21-31.

10. Pradhan R, Rajbhandari A, Manandhar P, Maharjan S. MCNamara Cephalometric Analysis of Newars of Kathmandu. Orthod J Nepal. 2018 June;8(1):14-7.

11. Pyakurel U, Thapaliya KB, Singh K, Gupta A, Gupta S, Bajracharya M, Shrestha RM. Assessment of Palatal Plane and Occlusal Plane for Determining Anteroposterior Jaw Relation. J Nepal Med Assoc. 2019;57(215):3-7.

12. Acharya A, Bhattarai B, George D, Bhagat T. Pattern of malocclusion in orthodontic patients in south-eastern region of Nepal. Orthod J Nepal. 2017;7(1):7-10.

13. Italia S, Bhatia AF. Palatal plane and their comparison with "Angle ANB" and "Wits Appraisal": A Cephalometric Study. The Journal of Ahmedabad Dental College and Hospital. 2011;2(1):22-6.

14. Rotberg S, Fried N, Kane J, Shapiro E. Predicting the "Wits" appraisal from the ANB angle. Am J Orthod. 1980;77(6):636-42.

15. Soliman NL, Batran MM, Tauwfik WA. Cephalometric assessment of sagittal relationship between maxilla and mandible among Egyptian children. Aust J Basic Appl Sci. 2009;3(2):706-1. 